\title{
Development of an application for mobile devices to evaluate the balance and risk of falls of the elderly
}

Luisa Veríssimo Pereira Sampaio Leonardo Braga Castilho² Gustavo de Azevedo Carvalho ${ }^{3}$

\section{Abstract}

Objective: to develop an application for mobile devices to evaluate the balance and risk of falls of the elderly. Method: A cross-sectional study with a sample composed of 54 elderly individuals with an average age of 71 years submitted to three balance and risk of falls evaluation tests, was performed. The Timed Up and Go (TUG) and Performance Oriented Mobility Assessment (POMA) tests were employed. Results: The results were closely correlated, identifying three groups of volunteers: low, medium and high risk of falls. When these values were compared with the analyzes performed by the application, some of the variations in the results generated by the application were not related to the classic tests, as the software could discriminate between individuals with a high and low risk of falls. Conclusion: The developed application was able to verify the oscillations present in the maintenance of static balance of the elderly and could differentiate the results into two groups of high and low risk of falls.

\footnotetext{
Universidade Católica de Brasília, Programa de mestrado em Gerontologia. Brasília, DF, Brasil.

2 Universidade de Brasília, Departamento de Matemática. Planaltina, DF, Brasil.

3 Universidade Católica de Brasília, Programa de Mestrado e Doutorado, Brasília, DF, Brasil.
}

Research funding: Distrito Federal Government - State Secretary for Science Technology and Innovation - Research Support Foundation (FAPDF). Notice 03/2014-PPSUS

Keywords: Gerontology. Accidental Falls. Physical Therapy. Smartphone. 


\section{INTRODUCTION}

Aging is defined as a natural and physiological process that progressively accompanies the life cycle. As well as psychosocial complications, physical losses also occur, resulting in slow reasoning, depression, functional disability, loss of strength, inactivity and physical degeneration. Active aging therefore contributes to the maintenance of functional capacity, the quality of life and the independence of the elderly ${ }^{1-3}$.

An aging population is more likely to suffer co-morbidities and all types of disabilities. The functional changes inherent in the aging process, such as decreased mobility and muscle strength, can lead to imbalance and consequently increase the risk of falls in the elderly. As it is known that falls in the elderly are associated not only with the use of medications, but also with factors such as frailty and functional loss, it is important to identify the risk associated with these events. Such elements can be classified as intrinsic when they are related to the physiological alterations of aging and extrinsic when related to social and environmental circumstances ${ }^{4-6}$.

It is important to develop preventive measures that describe the risk factors of this occurrence. The clinical approach should include a complete history of past falls and, additionally, an assessment of muscle strength and range of motion, as well as gait and balance tests. The application of the functional tests is intended to aid clinical evaluation by providing data on the patient's mobility capacity and revealing possible balance deficits. The main field tests are: the Timed Up and Go Test, the Berg balance scale, the functional reach test, the gait evaluation test and the Performance-oriented Mobility Assessment (POMA) ${ }^{7,8}$.

In terms of applicability, although many functional tests have been validated, the combined application of two or more instruments is required for greater data precision. The use of more accurate tools has also been suggested for the evaluation of the balance of this population. Technological advances allow the introduction and updating of techniques and procedures used by health professionals, such as the use of mobile devices as support instruments. Smartphones have major potential as accessible, practical and portable devices that can help in areas ranging from data collection procedures to assisting in the diagnosis of diseases and providing treatment advice ${ }^{9,10}$.

The use of smartphones in the area of health is growing as it provides professionals with more agility and flexibility in their work, from the time of data collection to the use of applications that assist with patient evaluation. The sensors embedded in these devices are increasingly being used in the evaluation of balance and gait. One of these sensors is the accelerometer, which has the potential to aid clinical procedures, offering quantitative data for assessment and balance and gait training ${ }^{11-13}$.

Given this scenario, the present study aimed to develop an application for mobile devices that assesses the balance and risk of falling among the elderly, and to compare the results provided by the application with the findings of the Timed Up and Go (TUG) and Performance-oriented Mobility Assessment (POMA) tests.

\section{METHOD}

The present experimental study was developed through stages of application development and testing.

First stage - development of application

A specialist company was contracted to develop a smartphone application capable of capturing and quantifying the anteroposterior and lateral oscillations of the human body in an orthostatic position for use by health professionals. The production instructions requested a user recognition area with $\log$-in and password; a patient registration area containing the fields name, telephone, date of birth, height and weight; a space to access and store patient information; a screen to perform a new analysis and the presentation of the results.

\section{Second stage - testing of application}

This stage of the study was carried out in a social center located in the Asa Sul region of Brasília, Distrito Federal, which serves about 300 elderly 
people. This institution offers water aerobics, swimming, dancing, Pilates, RPG, sewing classes, computers and languages to a community containing both active and sedentary elders. Those interested in participating in this research were asked to attend sessions on scheduled dates in August and September 2015 , in a room located in the social center itself, wearing gym clothes or clothes that allowed the mobility of the lower limbs.

The sample of this research was selected for convenience. Based on the inclusion criteria, active men and women who were able to understand the evaluator's instructions for performing the procedures were accepted. We excluded volunteers who presented physical and sensory limitations that made performing the functional, balance and gait tests difficult, as well as those who depended on aids to maintain balance, such as individuals with severe visual and auditory acuity, lower limb amputations, the use of prostheses or deterioration of the lower limbs, neurological diseases or who were unable to walk without assistance. The level of significance for the statistical analyzes was $95 \%$.

The selection of the volunteers was performed through a questionnaire, applied by an evaluator properly trained for the task, containing the following information: name, id number, age, gender, practice of physical activity, clinical history, reports of falls in last three years and fear of falling on a scale between 0 and 10.

The following were used for data collection: a Moto X Play model smartphone, a pouch with an adjustable strap to attach the device to the volunteer and the materials needed to apply the TUG and POMA tests.

The POMA (Performance-oriented Mobility Assessment) test is used to assess the risk of falls in the elderly through tasks involving static and dynamic balance, gait and turning. Each activity has a certain score ranging from 0 to 28 points in total. The evaluated individual is classified into one of three categories: normal, adaptive and abnormal ${ }^{14}$.

The TUG (Timed Up And Go) test assesses the mobility, balance, and risk of falls through sitting, standing, walking, turning, and sitting. The evaluated individual is classified based on the time taken to carry out the test and is classified into one of the three groups: independent (10 seconds or less), dependent for basic transfers (20 seconds or less) and highly dependent (more than 20 seconds) ${ }^{15,16}$. The questionnaires and evaluations were applied by the author of this study.

When able to participate in the research, volunteers underwent two phases of data collection: In the first, they were instructed to position themselves with their feet in parallel and to remain in this position for an analysis period of 20 seconds. The evaluator positioned the pouch with the adjustable belt in a centralized position relative to the center of mass anterior to the first or second sacral segment ${ }^{11}$, as shown in Figure 1. After the fixation of the device, the application was triggered by the evaluator to begin data collection. The duration of the analysis was timed by the software itself, demonstrating the beginning and the end of the procedure. Once the data were collected, the pouch was removed from the volunteer. The second phase of the collection consisted of applying the POMA test and after one minute of rest, the TUG test.

This study was submitted to the Ethics Committee of the Universidade Católica de Brasília (the Catholic University of Brasilia) and was approved in accordance with CNS Resolution 466/2012 and complementary guidelines, under opinion number: 681.473. 


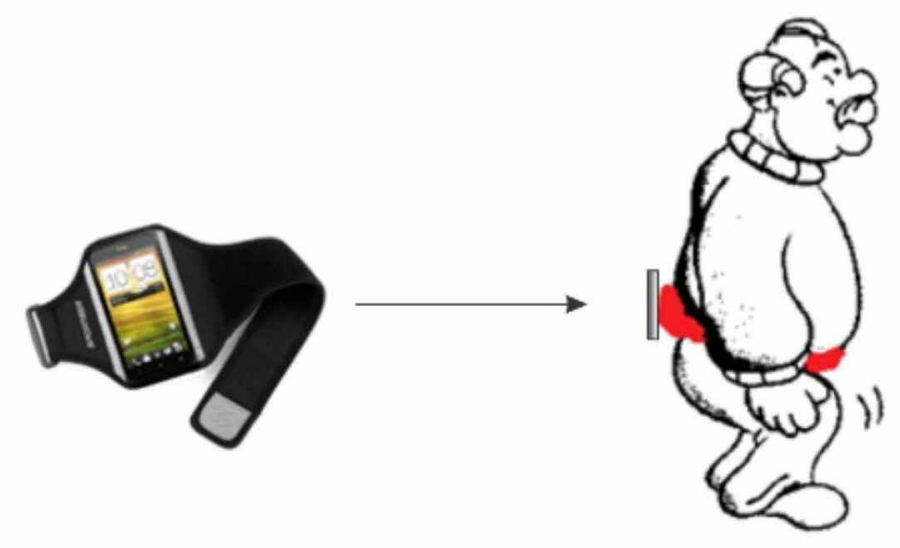

Figure 1. Fixation of device using pouch with adjustable belt. Brasília, Distrito Federal, 2016.

The evaluation data obtained with the application were stored and accessed by the Query language (SQL) database management system, visualized in the device itself, while the data referring to the POMA and TUG tests were recorded for later statistical analysis.

The difference between the means of the application results of the three risk groups was tested with variance analysis (ANOVA). A principal component analysis (PCA) test was performed using the TUG, POMA and application method results. The correlation of the three variables with the same factors indicates that the application is in accordance with the established methods.

\section{RESULTS}

The means of the application results were different for the three risk groups ( $\mathrm{F}=17,142.40$, $p<000.1)$. However, only the mean of the low-risk elderly persons was different from the other two groups, and the means of the medium and highrisk elderly persons did not differ (Tukey test: medium-low $=39.45, p<0.0001$, high-low $=41.23$, $p<0.001$, high-medium $=1.78, p=0.98)$. The methods of evaluation of the balance of the elderly correlated strongly with the first principal component (TUG: $\mathrm{r}=0.88, p<0.00001$; POMA: $\mathrm{r}=-0.92, p<0.0001$; App: $\mathrm{r}=0.77, p<0.0001)$. However, the application values also correlated relatively strongly with the second component $(\mathrm{r}=-0.62, p=0.00001)$, which corroborates the results of ANOVA.
First stage: development of application

The application was developed using the Virtual Studio and Xamarim Studio tools in C\# language with Framework.NET. The tool displays a screen for the identification and authentication of the user which is carried out by means of a register containing $\log$ in and password. After accessing the system, the evaluator has the option to access the database of previously collected results or perform a new analysis.

When choosing the new analysis option, the evaluator can determine the analysis time in seconds. The position of the accelerometer on the three perpendicular axes is used to form a sphere whose center is the initial position of the device fixed to the patient. Several different spheres are created for each patient during the analysis. Therefore, an increase in the standard deviation of the rays of these spheres represents an increase in the oscillation of the individual and a greater risk of falls. In this way the application effectively classifies these analyzes into low and high risks of falling.

To obtain the results, the ray of the sphere is initially applied with the formula:

$$
\mathrm{R}_{2}=2\left(\mathrm{x}-\mathrm{x}_{0}\right)+2\left(\mathrm{y}-\mathrm{y}_{0}\right)+2\left(\mathrm{z}-\mathrm{z}_{0}\right)
$$

Where:

$\mathrm{R}=$ ray of sphere; $x 0, y 0, z 0=$ coordinates of center of sphere with cartesian plane; and $x, y, z=$ sample obtained in analysis. 
Once the ray of all the samples were obtained, the mean and standard deviation were calculated, based on the formulas below:

$$
\begin{gathered}
R=1 N \sum N i=1 R i \text { (mean) } \\
\sigma=\left[1 N \sum N i=1(R i-R)\right] 1 / 2 \text { (standard } \\
\text { deviation) }
\end{gathered}
$$

Where:

$\mathrm{N}=$ number of samples; $\mathrm{P}=$ mean ray of analysis; $R i=$ ray of sample; and $\sigma=$ mean deviation.

It was found after the calculations that the results were around $10^{-2}$. Therefore, the product was produced from the result by the constant $10^{3}$, to make visualization by the user easier.

When the data was analyzed by distribution 35 was considered an effective value for classifying the groups, with results below this value representing a low risk of falling.

\section{Second stage - testing of application}

A total of 54 elderly persons took part in the present study, of whom six were men $(11.11 \%)$ and 48 were women $(88.88 \%)$. The mean age was equal to 71.3 (dp \pm 7.41 ) years (Max. 91 and Min. 60 years). In relation to the history of falls, 25 participants $(46.29 \%)$ said they had not suffered falls in the previous three years while eight volunteers $(14.81 \%)$ reported four or more fall events. When asked about fear of falling, using a scale of 0 to 10 , where 0 represents little fear and 10 is extremely fearful, 13 elderly people $(24.07 \%)$ said they had no fear of falling while eight (14.81\%) volunteers were very afraid of falling (score of 10 on the scale) as shown in Table 1:

The results of the TUG and POMA tests revealed a close correlation, allowing the volunteers to be classified into three groups of low, medium and high risks of fall. When these values were compared with the analyzes performed using the application, some of the results of the application did not relate to the classic tests, as the software did not differentiate between middle and high-risk elderly persons. These results are shown in Table 2 below, which describes the risk of falling results, and Figure 2 which denotes a boxplot chart showing the results of the application for the elderly, who were classified into three risk groups by the classic tests. The squares represent the means obtained by the application and the lines represent the mean plus +1 standard deviation or -1 standard deviation.

Tabela 1. Dados gerais da amostra referente ao presente estudo. Brasília, DF, 2016.

\begin{tabular}{ll}
\hline Variable & $\mathrm{N}(\%)$ \\
\hline Age (years) & \\
60 to 69 & $19(35.18 \%)$ \\
70 to 79 & $28(51.85 \%)$ \\
80 to 89 & $6(11.11 \%)$ \\
90 or more & $1(1.85 \%)$ \\
\hline Fall events & \\
No events & $25(46.29 \%)$ \\
1 event & $13(24.07 \%)$ \\
2 event & $3(5.55 \%)$ \\
3 events & $5(9.25 \%)$ \\
4 or more & $8(14.81 \%)$ \\
Fear of falling & \\
None $(0)$ & $13(24.07 \%)$ \\
A little (1 to 4$)$ & $13(24.07 \%)$ \\
Moderate $(5$ to 8$)$ & $16(29.62 \%$ \\
A lot $(9$ to 10$)$ & $12(22.22)$ \\
\hline
\end{tabular}


Continuation of Table 1

\begin{tabular}{ll}
\hline Variable & $\mathrm{N}(\%)$ \\
\hline Practice physical education & \\
Yes & $45(83.33 \%)$ \\
No & $9(16.66 \%)$ \\
\hline Frequency (times per week) & $3(6.81 \%)$ \\
Once a week & $11(25 \%)$ \\
Twice a week & $5(11.36 \%)$ \\
3 times a week & $11(25 \%)$ \\
4 times a week & $14(31.81 \%)$ \\
5 times a week & \\
Types & $5(7.57 \%)$ \\
Pilates & $22(33.33 \%)$ \\
Water aerobics & $14(21.21 \%)$ \\
Walking & $11(16.66 \%)$ \\
Gym & $14(21.21 \%)$ \\
(Capoeira, swimming, dancing, yoga, stretching, functional training) &
\end{tabular}

Table 2. Result of risk of fall tests with TUG and POMA tests and Application. Brasília, Distrito Federal, 2016.

\begin{tabular}{llll}
\hline Risk of falls & TUG Test & Poma Test & Application \\
\hline Low risk of falls & $39(72.22 \%)$ & $39(72.22 \%)$ & $28(65.11 \%)$ \\
Mean risk of falls & $9(16.66 \%)$ & $9(16.66 \%)$ & \\
High risk of falls & $6(11.11 \%)$ & $6(11.11 \%)$ & $15(34.88 \%)$ \\
\hline
\end{tabular}

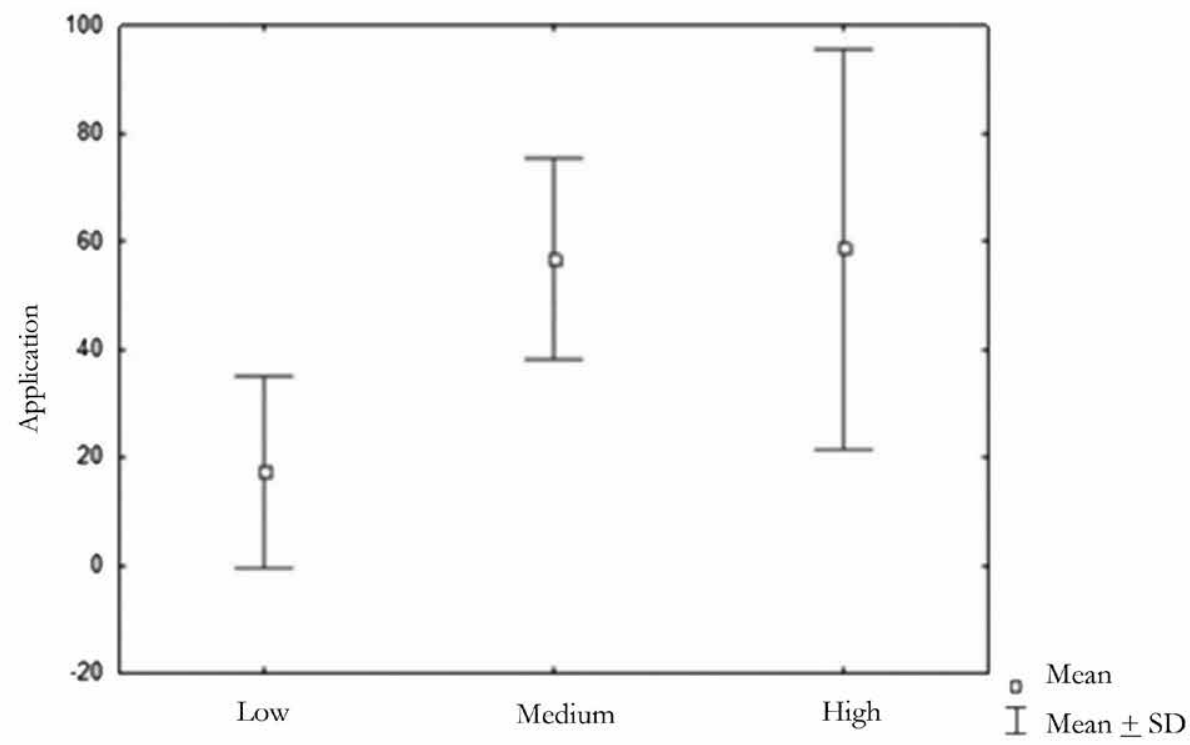

Risk of falls

Figure 2. Difference between mean oscillation identified with a smartphone application in elderly persons classified into three classes of risk by the POMA and TUG test. Brasília, Distrito Federal, 2016. 


\section{DISCUSSION}

The functional changes inherent in the aging process, such as decreased mobility and muscle strength, can lead to imbalance and consequently increase the risk of falls in the elderly. Human balance in the orthostatic position is complex, with the body in constant oscillatory movement remaining in a situation of balance through reverse compensation and on the same plane as the constant imbalances that occur in this position ${ }^{17,18}$.

With respect to the use of mobile devices as an instrument to aid the functional evaluation of the elderly, applications have been developed that support the execution and interpretation of tests of static balance, dynamic balance and gait. As in the present study, sensors similar to those found fixed to the ankle were attached to evaluate static balance by capturing oscillations in the maintenance of orthostatic posture. The volunteer was instructed to stand still during the test. After this step, a modified clinical test of sensory interaction of body balance was applied. The tool proved to be effective, with significant potential for assessing balance ${ }^{19}$.

In relation to static equilibrium, a study compared the results of equilibrium tests from three instruments: a stabilometry platform, an equilibrium platform and an application developed for this purpose. The participants were instructed to hold the device against their chests while they adopted different evaluation postures. The results showed that the application was effective, suggesting that it is a valid and consistent method ${ }^{20}$.

Like the previous study, an application was developed to aid in the assessment of unipedal balance. Volunteers were instructed to hold the device against their torsos while they stood on one leg (without the aid of the hands) on a stabilometry platform. The comparison between the two methods was also positive. Another study, meanwhile, compared the results obtained through five balance evaluation positions (parallel feet, heel to toe and single leg support) with data obtained by an application. The device measurements were also found to be reliable ${ }^{21,22}$.

Another study had the aim of comparing balance evaluation by computerized photogrammetry and an accelerometer. This research revealed that the accelerometer in the smartphone effectively evaluated the static balance of the elderly, and that the use of this instrument could describe the progress of patients and assist in physiotherapy treatment plans ${ }^{23}$.

One study aimed to develop an application that not only evaluated balance but allowed the possibility of balance training by verifying the results obtained by the device and through seven evaluation positions on the ground and on foam. The authors concluded that the application effectively assessed balance and allowed training for young adult volunteers ${ }^{24}$.

In order to develop a smartphone application to detect, reduce and eliminate the subjectivity of clinical trials, a study was carried out involving 20 elderly people who underwent the Tinetti and Timed Get Up and Go tests using a smartphone attached to the waist for data collection. The authors concluded that the results were valid, helping the examiner to detect characteristics of frailty and thus improving accuracy in diagnosis ${ }^{25,26}$.

As in the present study, the confidence of the data for the Timed Get Up and Go test collected through an iPhone 4 application was evaluated. Each participant performed the test three times wearing sensors positioned in the middle third of the sternum. It was concluded that the sensors incorporated into the iPhone 4 reliably identify kinematic standards in this test ${ }^{27}$.

Similarly, 30 volunteers, of whom 14 presented signs of frailty, were tested in five different steps: transfer from sitting to standing; go, turn gait; go and return gait; and turn and sit. The data collected by the smartphone were subsequently analyzed. It was concluded that the sensors present in the iPhone 4 were able to verify and analyze the different subphases present in the Timed Up and Go test in frail and non-frail elderly ${ }^{28}$.

With the purpose of analyzing the ability of a smartphone application to evaluate the sit and stand and single leg balance tests authors attached the mobile device to different segments, using the upper region of the torso in the first study ${ }^{29}$ and the lumbar spine in the second $\mathrm{d}^{30}$. Both obtained positive results compared to other forms of evaluation. 
There was no agreement between the studies in terms of the functional tests applied to compare the results provided by the mobile devices. Similarly, there was no consensus as to whether or not a fixture attachment is required, or the best region for attachment.

\section{CONCLUSION}

Based on the results of this study it was concluded that the final version of the developed application was able to verify the oscillations present in the

\section{REFERENCES}

1. Neto MP. O estudo da velhice: histórico, definição do campo e termos básicos. In: Freitas EV, Py L, Cançado FAX, Doll J, Gorzoni ML. Tratado de geriatria e gerontologia. $2^{\mathrm{a}}$ ed. Rio de Janeiro: Guanabara Koogan; 2011. Cap. 1, p. 2-22.

2. Santos SSC. A gerontologia à luz da complexidade de Edgar Morin. Rev Eletr Mestr Educ Ambient. 2004;V. Esp:1-14.

3. Souza MAH, Porto EF, Souza EL, Silva KI. Perfil do estilo de vida de longevos. Rev Bras Geriatr Gerontol [Internet]. 2016 [acesso em 04 nov. 2016];19(5):819-26. Disponível em: http://www. scielo.br/scielo.php?script $=$ sci_arttext\&pid $=$ S1809$98232016000500819 \& \operatorname{lng}=$ en\&nrm $=$ iso\&tlng=pt

4. Miranda GMD, Mendes ACG, Silva ALA. Population aging in Brazil: current and future social challenges and consequences. Rev Bras Geriatr Gerontol [Internet]. 2016 [acesso em 06 nov. 2016];19(3):507-19.Disponível em: http://www. scielo.br/scielo.php?script $=$ sci_arttext\&pid=S180998232016000300507\&lang=pt

5. Cruz DT, Duque RO, Leite ICG. Prevalência do medo de cair em uma população de idosos da comunidade. Rev Bras Geriatr Gerontol [Internet]. 2017 [acesso em 01 ago. 2017];20(3):30918. Disponível em: http://www.scielo.br/ scielo.php?script $=$ sci_arttext\&pid=S1809 98232017000300309\&lng=en\&nrm=iso\&tlng=pt

6. Alves RLT, Silva CFM, Pimentel LN, Costa IA, Souza ACS, Coelho LAF. Avaliação dos fatores de risco que contribuem para queda em idosos. Rev Bras Gerontol Gerontol [Internet]. 2017 [acesso em 05 ago. 2017];20(1):59-69. Disponível em: http://www. redalyc.org/html/4038/403850707006/ maintenance of the static balance of the elderly and to separate the results into high and low risk of fall groups. Despite the positive results, more tests should be performed to implement new functionalities and technical adjustments to improve this software.

Mobile devices have great potential as a support tool for health professionals. It is also important to highlight the key role of these professionals in gerontology technology, with the objective of developing and validating reliable tools. Further research is therefore necessary to prove the reliability and validation of the results.

7. Gravasso WC, Beltrame V. Capacidade funcional e morbilidades referidas: Uma análise comparativa em idosos. Rev Bras Geriatr Gerontol [Internet]. 2017 [acesso em 20 ago. 2017];20(3):399-409. Disponível em: http://www.scielo.br/pdf/rbgg/v20n3/pt_18099823-rbgg-20-03-00398.pdf

8. Neri AL. Palavras chave em gerontologia. Campinas: Alínea; 2008.

9. Nakamura EF. Computação móvel: novas oportunidades e novos desafios. T\&C Amazônia. 2003;1(2):16-28.

10. Mosa MAS, Yoo I, Sheets L. A systematic reveiew of heathcare applications for smartphones. BMC Med Inform decis mak. 2012;12:1-37.

11. Sabbatini RME. Telemedicina e Informatização em Saúde. In: Siqueira E, Organizador. Technologies That Change Our Lives. São Paulo: Saraiva; 2007. Cap. 5, p. 147-79.

12. Culhane KM, Connor MO, Lyons D, Lyons GM. Accelerometers in rehabilitation medicine for older adults. Age Ageing. 2005;34(6):556-60.

13. Hlavačka F, Bzdúšková D, Halická Z, Lobotková J, Szathmáry V. Assessment of Human Balance during Stance using Accelerometer Sensors. In: Measurement. Proceedings of the 8th International Conference; 2011 Apr. 27-30; Smolenice Castle, Slovakia. Slovakia: Institute of Measurement Science; 2011.

14. Brandão AKU, Pessoa AB, Cardoso JM, Meireles FMM, Nascimento PRM, Duarte DM, et al. Uso de instrumentos para investigação do equilíbrio postural em tarefas funcionais. Fisioter Bras. 2016;17(6):585-95.

15. Rodrigues MMP, Falcão RMM, Veras RFS, Barbosa KTF, Oliveira FMRL, Pereira MA, et al. Timed Up And Go predictor of falls in elderly people residing in the comunity? Int Arch Med. 2017;10(146):1-6. 
16. Guerra HS, Bernardes DCF, Santana JA, Barreira LM, Sousa RA, Neves CM. Avaliação do risco de quedas em idosos da comunidade. Rev saúde.com. 2017;13(2):879-86.

17. Lima JP, Farensena B. Aplicação do teste Poma para avaliar o risco de quedas em idosos. Geriatr Gerontol. 2012;6:200-11.

18. Bienfait M. Os Desequilíbrios estáticos: Filosofia, patologia e tratamento fisioterápico. Angela S, tradutora. $4^{a}$ ed. São Paulo: Summus; 1995. Cap. 2, Fisiologia estática e suas perturbações; p. 24-9.

19. Vieira JC. Sistema de mensuração da oscilação dos membros inferiores para testes de equilíbrio corporal [Trabalho de conclusão de curso]. Natal: Universidade Federal do Rio Grande do Norte; 2015

20. Rohleder PA. Validation of balance assessment measures of an accelerometric mobile device application versus a balance plataform [Thesis Internet]. Wichita: Wichita state University; 2012 [acesso em 20 nov. 2016] disponível em: https:// swaymedical.com/wp-content/themes/sway/library/ files/research/VALIDATION-OF-BALANCEFROM-MOBILE-DEVICE-APPLICATIONVERSUS-A-BALANCE-PLATFORM.pdf

21. Patterson JA, Amik RZ, Thummar T, Rogers ME. Validation of measures from the smartphone sway balance application: a pilot study. Int J Sports Phys Ther. 2014;9(2):135.

22. Amik RZ, Chaparro A, Patterson JA, Jorgensen MJ. Test-retest reliability of the sway balance mobile application. J Mobile Technol Med. 2015;4(2):40-7.

23. Oliveira DS, Oltramari G, Shuster RC, De Oliveira DTC. Comparação do equilíbrio estático de idosas avaliadas por meios de dois métodos: fotogrametria computadorizada e acelerômetro. Fisioter Mov. 2015;28(2):349-56.
24. Franco C, Fleury A, Guméry P, Diot B, Demongeot J, Vuillerme N. iBalance-ABF: a smartphone-based Audio-Biofeedback Balance System. IEEE Trans Biomed Eng. 2013;60(1):211-5.

25. Fontecha J, Hervás R, Bravo J, Navarro FJ, Sánchez L. A proposal for elderly frailty detection by using accelerometer-enabled smartphones. In: 5th international symposium of Ubiquitous Computing and Place Intelligence, 2008; Oslo. UIC; 2011.

26. Fontecha J, Hervás R, Bravo J, Navarro FJ. A mobile and ubiquitous approach for supporting frailty assessment in elderly people. J med Internet res [Internet]. 2013 [acesso em 12 maio 2015];15(9):197. Disponível em: https://www.ncbi.nlm.nih.gov/pmc/ articles/PMC3785993/https://www.ncbi.nlm.nih. gov/pmc/articles/PMC3785993/

27. Mercant AG, López FJB, Manzanares MTL, Vargas AIC. Reliability and critrerion-related validity with a smartphone used in timed up and go test. Biomed. Eng [Internet]. 2014 [acesso em 12 maio 2015];13:1-14. Disponível em: https://biomedical-engineering-online. biomedcentral.com/articles/10.1186/1475-925X-13-156.

28. Ferreira MIT. O uso do smartphone na avaliação do risco de queda associado ao envelhecimento [dissertação]. Porto: Escola Superior de Tecnologia da Saúde do Porto, Instituto Politécnico do Porto; 2013.

29. Tarrio I, Melo CA, Montes AM, Castro C, Santos MR. O uso do smartphone na avaliação do risco de queda associado ao envelhecimento [Dissertação]. Porto: Escola superior de tecnologia da saúde do Porto; 2013.

30. Cerrito A, Bichsel L, Radlinger L, Schmid S. Reliability and validity of a smartphone-based application for the quantification of the sit-tostand movement in health seniors. Gait Posture. 2015;41(2):409-13. 